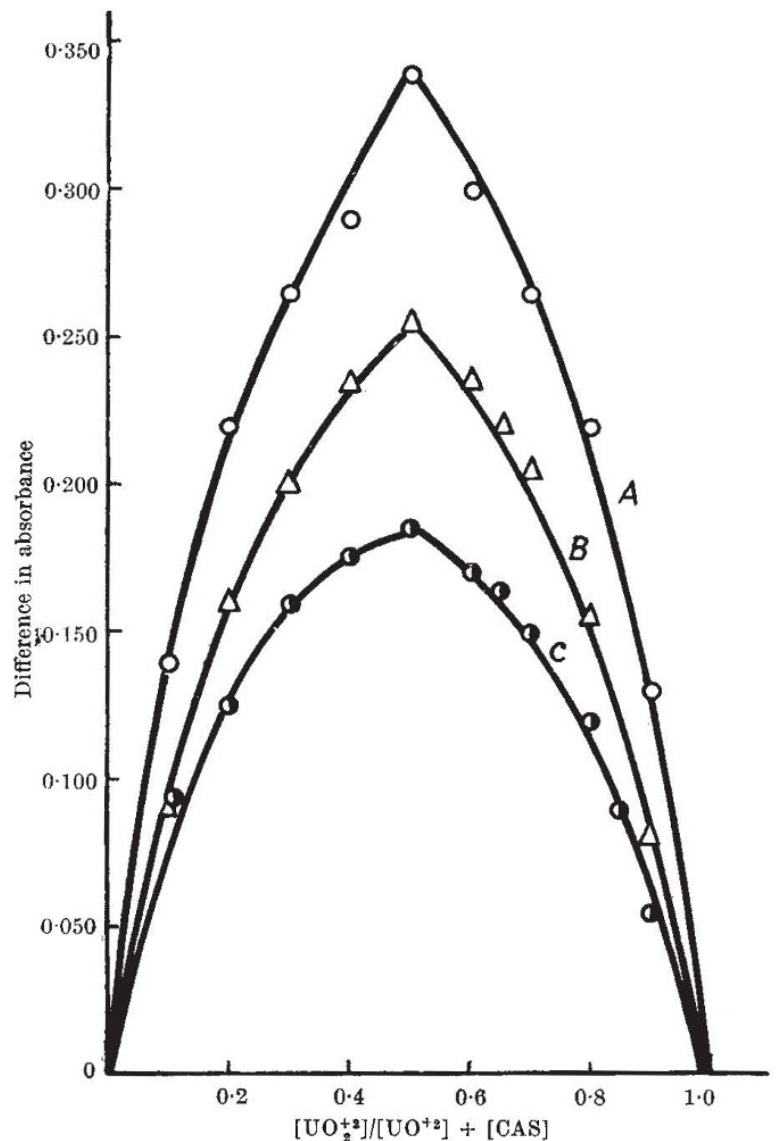

Fig. 1. Determination of the composition from absorption spectra studies at $435 \mathrm{~m} \mu$ (equimolecular solutions). Curve $A, c=2 \cdot 0 \times 10^{-3} \mathrm{M}$,
$p=1$; curve $B, c=1 \cdot 33 \times 10^{-3} \mathrm{M}, p=1$; curve $C, c=1.0 \times 10^{-3} \mathrm{M}, p=1$

from absorbance data using the method of Dey et al. ${ }^{11}$, is $7 \cdot 14 \pm 0 \cdot 11$ at $25^{\circ} \mathrm{C}$. The free energy of formation $\Delta \mathrm{F}^{0}$ of the chelate corresponds to $-9 \cdot 85 \pm 0 \cdot 15$ cal. at $25^{\circ} \mathrm{C}$.

SAMIR K. BANERJI* Arun K. Dey

Chemical Laboratories,

University of Allahabad.

* Present address : Chemistry Department, Birla Engineering College, Pilani, India.

1 Mathur, K. C., and Dey, A. K., Z, anal. Chem, 154, 347 (1958),

${ }^{2}$ Sommer, L., Chim. Iisty, 51, 340 (1958).

${ }^{\text {a }}$ Shnaiderman, S. Хa, Zhur. neorg. Khim., 2, 2122 (1957).

- Babko, A. K., and Papova, O. I., Zhur. neorg. Khim, 2, 138 (1957).

'Okăc, A., and Sommer, L., Chim. Listy, 50, 1171 (1956).

- Sommer, L., Intern. Conf. Co-ordination Chemistry, Rome (1957).

${ }^{7}$ Sommer, L., Symp. Chem. Co-ordination Compounds, Agra (1959).

${ }^{6}$ Ware, E., U.S. Atomic Energy Comm. Rep. MDDC, 1432 (1945).

- Mukherji, A. K., and Dey, A. K., J. Ind. Chem. Soc., 35, 113 (1958).

${ }^{10}$ Vosburgh, W. C., and Cooper, G. R., J. Amer. Chem. Soc., 63, 437 (1941).

${ }^{11}$ Mukherji, A. K., and Dey, A. K., J. Inorg. Nucl. Chem., 6, 314 (1958).

\section{Coding of Open and Closed Carbon Chains}

Is a previous communication ${ }^{1}$, a method of coding openended carbon chains was suggested, which amounted, in effect, to forming the autocorrelation function of the net. This code had the advantage of being nearly unambiguous, but sufferod from the drawback that, while the code of any given net could be determined straightforwardly, the not corresponding to a given code could not. A. Savitzky has suggested (private eommunication) that, nevortheless, this code could be useful as a chock; that is, if added to the usual chemical name of a given compound, this code could serve to verify whether the topology of the compound reconstructed from the name is the correct one.
If so used as a check, complete unambiguity is of lesser importance, and a probabilistic point of view can be adopted. Thus, if a $C_{n}$ net can have $N(n)$ different possible configurations, and if there are $m(n)$ ambiguities, the probability that, once having roconstructed the incorrect configuration, the code of this configuration is identical to the code of the correct configuration can be written as:

$$
p=\frac{2 m}{N(N-1)}
$$

With this fresh point of view, the question was then examined whether, when extending the code proposed to nets containing closed chains, the appreciable number of ambiguities encountered would still loave $p$ tolerably small, and whether $p$ would tend to decrease for increasing $n$.

The postulate was made, when making this extension, that rings of 5, 6 and 7 carbon atoms only would enter into consideration. The code was formed, in line with the procedure followed for open chains, by counting the number of poirs of carbon atoms at minimum distances 3,4 , etc.

Table 1

\begin{tabular}{rrrcrc} 
& \multicolumn{5}{c}{ Table 1 } \\
$n$ & $N$ & $m$ & $p$ & $m_{1}$ & $p_{1}$ \\
7 & 15 & 0 & 0 & 0 & 0 \\
8 & 34 & 4 & $0 \cdot 71 \%$ & 0 & 0 \\
9 & 85 & 13 & $0 \cdot 36 \%$ & 4 & $0 \cdot 14 \%$ \\
10 & 220 & 50 & $0 \cdot 21 \%$ & 24 & $0 \cdot 24 \%$
\end{tabular}

'The findings are summarized in Table 1 in which the number of ambiguities wore counted as 1,3 , 6, etc., for the double, triple, quadruple, etc., occurrence of the same code. The conclusion, implicit in the fourth column, is that $p$ exhibits a satisfactory tendency to decrease with increasing $n$.

When extended to closed chains, the location code, formed by counting, for any one carbon atom, the number of other carbon atoms at distances 1, 2, etc., appears to be less satisfactory for increasing numbers of atoms. The probability of determining an erroneous position having the same location code as the correct one, $p_{1}=\frac{2 m_{1}}{N n(n-1)}$ where $m_{1}$ designates the number of location ambiguities (not counting those due to the molecule symmetry) is indicated in the last column.

I thank Prof. A. I. M. Keulemans, who directed my attention to this problem, and Prof. C. Koningsberger for a discussion of the most reasonable postulates to be made for closed chains.

\section{Marcel J. E. GoJ,AX}

Technische Hogeschool, Eindhoven.

${ }^{1}$ Golay, M. J. E., Nature, 193, 1072 (1962).

\section{Existence of Two Soil Species in Detergency Investigations}

Aтtночян a considerable amount of research has been devoted to the examination of detergency, little work has been done on rates of soil removal. Durham ${ }^{1}$ has commented on the need for kinetic studies in detorgency research. We have examined the kinetics of detergency in a model circulation cleaning system. In this model systom a detergent solution $(0.03 \mathrm{M}$ sodium hydroxide) is pumped from a 50-gallon tank through a short length of $1 \frac{1}{2}$-in. diam. pipe in a elosod system. Test strips of stainless steel $3.6 \mathrm{~cm} \times 32 \mathrm{~cm}$ are soiled on one side with a very thin layor of pure synthetic tristearin labelled with carbon-14. The test strip is placed in the pipe, the detergent solution is pumped past tho strip for a fixed time undor closely controlled conditions aftor which the pipe is drained and the strip is removed. The amount of tristearin taken off the strip is found by measuring the radioactivity before and after each treatment. By means of repeated cleaning treatments on one strip, a cleaning curve is obtained. 